\title{
Effective Gaseous Diffusion Coefficients of Select Ultra-fine, Super- fine and Medium Grain Nuclear Graphite
}

\author{
J. J. Kane, A. C. Matthews, C. J. Orme, C. \\ I. Contescu, W. D. Swank, W. E. Windes
}

September 2018

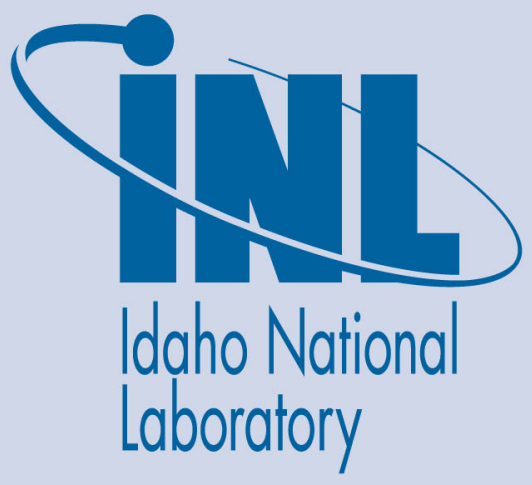

The INL is a U.S. Department of Energy National Laboratory operated by Battelle Energy Alliance 


\title{
Effective Gaseous Diffusion Coefficients of Select Ultra-fine, Super-fine and Medium Grain Nuclear Graphite
}

\author{
J. J. Kane, A. C. Matthews, C. J. Orme, C. I. Contescu, W. D. Swank, W. E. Windes
}

September 2018

Idaho National Laboratory Idaho Falls, Idaho 83415

http://www.inl.gov

Prepared for the

U.S. Department of Energy

Under DOE Idaho Operations Office

Contract DE-AC07-05ID14517 


\section{Effective Gaseous Diffusion Coefficients of Select Ultra-fine, Super-fine and Medium Grain Nuclear Graphite}

Joshua J. Kane ${ }^{1 *}$, Austin C. Matthews ${ }^{1}$, Christopher J. Orme ${ }^{2}$, Cristian I. Contescu ${ }^{3}$, W. David Swank $^{1}$, William E. Windes ${ }^{1}$

1-Materials Science \& Engineering Department, Energy \& Environmental Science and Technology, Idaho National Laboratory, Idaho Falls, ID 83415, USA

2-Biological \& Chemical Processing Department, Energy \& Environmental Science and Technology, Idaho National Laboratory, Idaho Falls, ID 83415, USA

3-Materials Science and Technology Division, Oak Ridge National Laboratory, Oak Ridge, TN, USA 


\begin{abstract}
Understanding "Where?” and "How much?” oxidation has occurred in a nuclear graphite component is critical to predicting any deleterious effects to physical, mechanical, and thermal properties. A key factor in answering these questions is characterizing the effective mass transport rates of gas species in nuclear graphites. Effective gas diffusion coefficients were determined for twenty-six graphite specimens spanning six modern grades of nuclear graphite. A correlation was established for the majority of grades examined allowing a reasonable estimate of the effective diffusion coefficient to be determined purely from an estimate of total porosity. The importance of Knudsen diffusion to the measured diffusion coefficients is also shown for modern grades. Knudsen diffusion has not historically been considered to contribute to measured diffusion coefficients of nuclear graphite.
\end{abstract}




\section{Nomenclature}

All symbols are nominally listed in order of appearance.

\begin{tabular}{|c|c|c|c|}
\hline Symbol & Description & Units & Equation(s) \\
\hline $\boldsymbol{n}_{\boldsymbol{i}_{\text {in }}}$ & $\begin{array}{l}\text { The molar flow rate of gas into side } i \text { of the diffusion } \\
\text { cell. In figure } 2, i \text { is the top or bottom half of the cell. }\end{array}$ & $\mathrm{mol} / \mathrm{min}$ & $1-5$ \\
\hline $\boldsymbol{n}_{i_{\text {out }}}$ & $\begin{array}{c}\text { The molar flow rate of gas out of side } i \text { of the } \\
\text { diffusion cell. In figure } 2, i \text { is the top or bottom half } \\
\text { of the cell. }\end{array}$ & $\mathrm{mol} / \mathrm{min}$ & $1-5$ \\
\hline$y_{i_{i n}}$ & $\begin{array}{c}\text { The mole fraction of chosen gas species on side } i \text { of } \\
\text { diffusion cell just prior to reaching the porous } \\
\text { graphite plug. }\end{array}$ & Unitless & 3-5 \\
\hline$y_{i_{\text {out }}}$ & $\begin{array}{l}\text { The mole fraction of chosen gas species on side } i \text { of } \\
\text { diffusion cell just after passing over porous graphite } \\
\text { plug. The gas is assumed to mix instantaneously. }\end{array}$ & Unitless & $3-5$ \\
\hline$n_{1 \rightarrow 2}$ & $\begin{array}{l}\text { The flow of chosen gas species, through the porous } \\
\text { graphite plug, from side } 1 \text { to side } 2 \text { of the diffusion } \\
\text { cell }\end{array}$ & $\frac{\mathrm{mol}}{\min }$ & $3-5$ \\
\hline$n_{2 \rightarrow 1}$ & $\begin{array}{l}\text { The flow of chosen gas species, through the porous } \\
\text { graphite plug, from side } 2 \text { to side } 1 \text { of the diffusion } \\
\text { cell. }\end{array}$ & $\frac{\operatorname{mol}}{\min }$ & 3-5 \\
\hline$N_{A}, N_{B}$ & The molar flux of species A and B, respectively. & $\frac{\mathrm{mol}}{\mathrm{cm}^{2} \min }$ & $6-8 \mathrm{a}$ \\
\hline$D_{E f f_{A}}$ & $\begin{array}{l}\text { The effective diffusion coefficient of species A } \\
\text { through a particular porous medium. The gas is } \\
\text { assumed here to be composed of species A and B. }\end{array}$ & $\frac{\mathrm{cm}^{2}}{\min }$ & $6,9-11,13$ \\
\hline$y_{A}$ & $\begin{array}{l}\text { The mole fraction of species A in a binary mixture of } \\
\text { gases A and B. }\end{array}$ & Unitless & 6,13 \\
\hline$M_{A}, M_{B}$ & $\begin{array}{l}\text { The molecular weights of gas species A and B, } \\
\text { respectively. }\end{array}$ & $\frac{g}{m o l}$ & 7,12 \\
\hline C & The concentration of gas in diffusion cell. & $\mathrm{mol} / \mathrm{cm}^{3}$ & 6,8 \\
\hline$L$ & $\begin{array}{l}\text { The measured thickness of the porous plug parallel to } \\
\text { the direction of mass transport. }\end{array}$ & $\mathrm{cm}$ & 8 \\
\hline$\alpha$ & Defined by the relationship given in Equation 8a & Unitless & $8,8 \mathrm{a}, 13$ \\
\hline$D_{A B}$ & $\begin{array}{c}\text { The normal diffusion coefficient for species } \mathrm{A} \text { in a } \\
\text { binary mixture of species A and B. }\end{array}$ & $\mathrm{cm}^{2} / \min$ & $9,11,13$ \\
\hline$f$ & $\begin{array}{l}\text { A pore structural factor defined by equation } 9 . \text { A } \\
\text { subscript of } \mathrm{N} \text { or } \mathrm{K} \text { represents structural factors for } \\
\text { pore within the normal and Knudsen diffusion } \\
\text { regime, respectively. }\end{array}$ & Unitless & $9,10,13$ \\
\hline$\phi$ & Open porosity of a porous material & Unitless & $9-11$ \\
\hline$\sigma$ & $\begin{array}{l}\text { A constriction factor for changing pore cross-section } \\
\text { along the length of a pore. }\end{array}$ & Unitless & 9,11 \\
\hline
\end{tabular}




\begin{tabular}{cccc}
\hline Symbol & Description & Units & Equation(s) \\
\hline $\boldsymbol{\tau}$ & $\begin{array}{c}\text { Geodesic tortuosity. The ratio of the geodesic path } \\
\text { length of a pore relative to the Euclidean distance } \\
\text { traveled across the porous material. }\end{array}$ & Unitless & 9,11 \\
$\left\langle\boldsymbol{v}_{\boldsymbol{A}}\right\rangle$ & $\begin{array}{c}\text { Arithmetic mean gas molecule velocity assuming a } \\
\text { Boltzmann energy distribution. }\end{array}$ & $\mathrm{m} / \mathrm{s}$ & 12 \\
$\boldsymbol{k}$ & Boltzmann constant & $\mathrm{kg} \mathrm{m} / \mathrm{s}^{2} \mathrm{~K}$ & 12 \\
$\boldsymbol{T}$ & Temperature & $\mathrm{K}$ & 12 \\
$\boldsymbol{D}_{\boldsymbol{K}_{\boldsymbol{A}}}$ & Knudsen diffusion coefficient for species A & $\mathrm{cm}^{2} / \mathrm{min}$ & 13 \\
\hline
\end{tabular}

\section{Introduction}

Environmental concerns regarding greenhouse gas emissions have led to the pursuit of lowcarbon-emitting energy technologies to curb future carbon dioxide emissions. With continually increasing energy demands, nuclear power is one attractive alternative energy source with lowcarbon-emissions, constant power supply, and a high energy density.

Among nuclear power reactor options, graphite reactors such as the high temperature gas-cooled reactor (HTGR) represent an alternative to the more common water-moderated light water reactors for the generation of electrical power. In addition to several inherent safety features, the nuclear heat supply for more recent modular HTGR designs allows for core outlet temperatures in the range of $700-850^{\circ} \mathrm{C}$ [1]. This enables heat to be converted to electricity at high conversion efficiencies as well as providing a versatile energy source for a wide range of energy-intensive industrial processes [2].

With new HTGR operating licenses anticipated to allow operations for longer than 60 years, both long- and short-term corrosion of the graphitic components must be considered [3]. While oxidation is not a major concern for day-to-day operation, the oxidation of graphite in HTGRs needs to be considered (1) due to chronic oxidation via small amounts of oxidizing impurities, with $\mathrm{H}_{2} \mathrm{O}$ as the major impurity of interest and (2) due to the extremely unlikely case of acute oxidation in the case of an off-normal event followed by air ingress. Both conditions will lead to degradation of the mechanical, physical, and thermal properties of graphite components and these degradations, in turn, can detrimentally affect reactor performance and possibly safety. Research efforts have focused on the determination of kinetic rate laws for various grades of graphite [4-14], but little attention has been given to characterizing the rate of gas transport 
through nuclear graphite. The limited studies that do exist are mostly from U.K researchers in the 1960s. These studies primarily investigated grades using large grain sizes for filler material [15$25]$ and are considerably different from current nuclear graphite grades of interest. In order to predict the effects of damage and degradation from oxidation, one must know how deep the oxidizing reactants penetrate into pore structures as well as how much oxidation has occurred locally within an exposed pore structure. In other words, both the reaction kinetics and the effective gas transport must be well understood. This paper provides an initial assessment of gas transport rates through the experimental determination of effective diffusion coefficients for several modern fine- and medium-grain nuclear graphites.

\section{Experimental}

\subsection{Materials}

The gases utilized for this study were ultra-high-purity (UHP) argon (Ar) and nitrogen $\left(\mathrm{N}_{2}\right)$. The certificate of analysis claimed a purity $>99.999 \%$. Ar and $\mathrm{N}_{2}$ were chosen for this study for two reasons (1) Ar and $\mathrm{N}_{2}$ have relatively weak interactions with graphite at room temperature (2) Of the gas species of interest to an HTGR environment, $\mathrm{He}(\sim 4 \mathrm{amu}), \mathrm{H}_{2} \mathrm{O}(\sim 18 \mathrm{amu}), \mathrm{CO}(\sim 28$ $\mathrm{amu}), \mathrm{N}_{2}(\sim 28 \mathrm{amu}), \mathrm{O}_{2}(\sim 32 \mathrm{amu})$ and $\mathrm{CO}_{2}(\sim 44 \mathrm{amu}), \operatorname{Ar}(\sim 40 \mathrm{amu})$ and $\mathrm{N}_{2}$ provided a reasonable mass range for a majority of the species. Combined, these two factors were expected to provide representative measurements of effective diffusivities. In addition, a custom certified gas mixture, composed of equal parts argon, nitrogen, hydrogen, and helium (all $25 \% \pm 0.5 \%$ ) by volume) was used for calibration. All gases were purchased from NorLab, a division of Norco, Inc.

Twenty-six graphite samples were analyzed between six nuclear grades. For each grade, a minimum of 4 samples were examined. The grades examined are listed below in Table 1 .

Table 1.

\begin{tabular}{|c|c|c|c|c|c|c|}
\hline Grade & Vendor & $\begin{array}{c}\text { Grain } \\
\text { Designation }\end{array}$ & $\begin{array}{l}\text { Grain } \\
\text { Size }\end{array}$ & $\begin{array}{l}\text { Coke } \\
\text { Type }\end{array}$ & $\begin{array}{c}\text { Fabrication } \\
\text { method }\end{array}$ & $\begin{array}{c}\text { Density } \\
\left(\mathrm{g} / \mathrm{cm}^{\mathbf{3}}\right) \\
\boldsymbol{\mu} \pm \sigma^{\star}\end{array}$ \\
\hline 2114 & Mersen & Super-fine & $13 \mu \mathrm{m}^{\dagger}$ & Pitch & Iso-molded & $\begin{array}{c}1.817 \\
\pm 0.002\end{array}$ \\
\hline$I G-110$ & $\begin{array}{l}\text { Toyo } \\
\text { Tanso }\end{array}$ & Super-fine & $20 \mu \mathrm{m}^{\dagger}$ & Petroleum & Iso-molded & $\begin{array}{c}1.770 \\
\pm 0.016\end{array}$ \\
\hline
\end{tabular}




\begin{tabular}{|c|c|c|c|c|c|c|c|}
\hline$I G-430$ & $\begin{array}{l}\text { Toyo } \\
\text { Tanso }\end{array}$ & Ultra-fine & $10 \mu \mathrm{m}^{\dagger}$ & Pitch & Iso-molded & $\begin{array}{c}1.810 \\
\pm 0.004\end{array}$ & 4 \\
\hline$N B G-17$ & SGL & Medium & $0.8 \mathrm{~mm}^{*}$ & Pitch & $\begin{array}{l}\text { Vibra- } \\
\text { molded }\end{array}$ & $\begin{array}{c}1.820 \\
\pm 0.005\end{array}$ & 4 \\
\hline$N B G-18$ & SGL & Medium & $1.6 \mathrm{~mm}^{*}$ & Pitch & $\begin{array}{l}\text { Vibra- } \\
\text { molded }\end{array}$ & $\begin{array}{c}1.846 \\
\pm 0.002\end{array}$ & 4 \\
\hline$P C E A$ & Graftech & Medium & $0.8 \mathrm{~mm}^{*}$ & Petroleum & Extruded & $\begin{array}{c}1.845 \\
\pm 0.007\end{array}$ & 4 \\
\hline
\end{tabular}

Graphite samples were machined into rectangular cuboids from their respective graphite billets using electron-discharge machining. Machined sample dimensions were $25.197 \mathrm{~mm} \times$ $25.197 \mathrm{~mm} \times 11.938 \mathrm{~mm}$, with a dimensional tolerance of $\leq 0.051 \mathrm{~mm}$ along each dimension. The sample thickness was chosen to balance two competing factors: (1) a thickness great enough to reasonably represent mass transport though the bulk material, and (2) samples thin enough to achieve a diffusive flux large enough to equate to a measurable outlet concentration well above the inherent impurity levels in the UHP gases used. The mass and sample volume of each cuboid was measured to determine sample density. Each sample was thoroughly washed, sonicated in water, cleaned, and dried in a $200^{\circ} \mathrm{C}$ oven prior to mass and volumetric measurements.

\subsection{Experimental apparatus}

The experimental apparatus was custom-built at Idaho National Laboratory. The cell design is similar to the classic Wicke-Kallenbach diffusion cell [26] and is schematically illustrated in Fig. 1. The cell was designed to maintain a uniform, unidirectional flow over the porous sample while maintaining the flexibility to accommodate a variety of sample thicknesses and geometries with minimal modification. The cell was designed as three pieces. The two outer pieces were machined identically and contain the channels for gas flow while the center piece was a polished steel plate with a precision machined slot to fit samples of the desired dimensions. The piping upstream and downstream of the cell was meticulously cut, bent, and deburred to minimize differences in frictional losses on either side of the cell. 


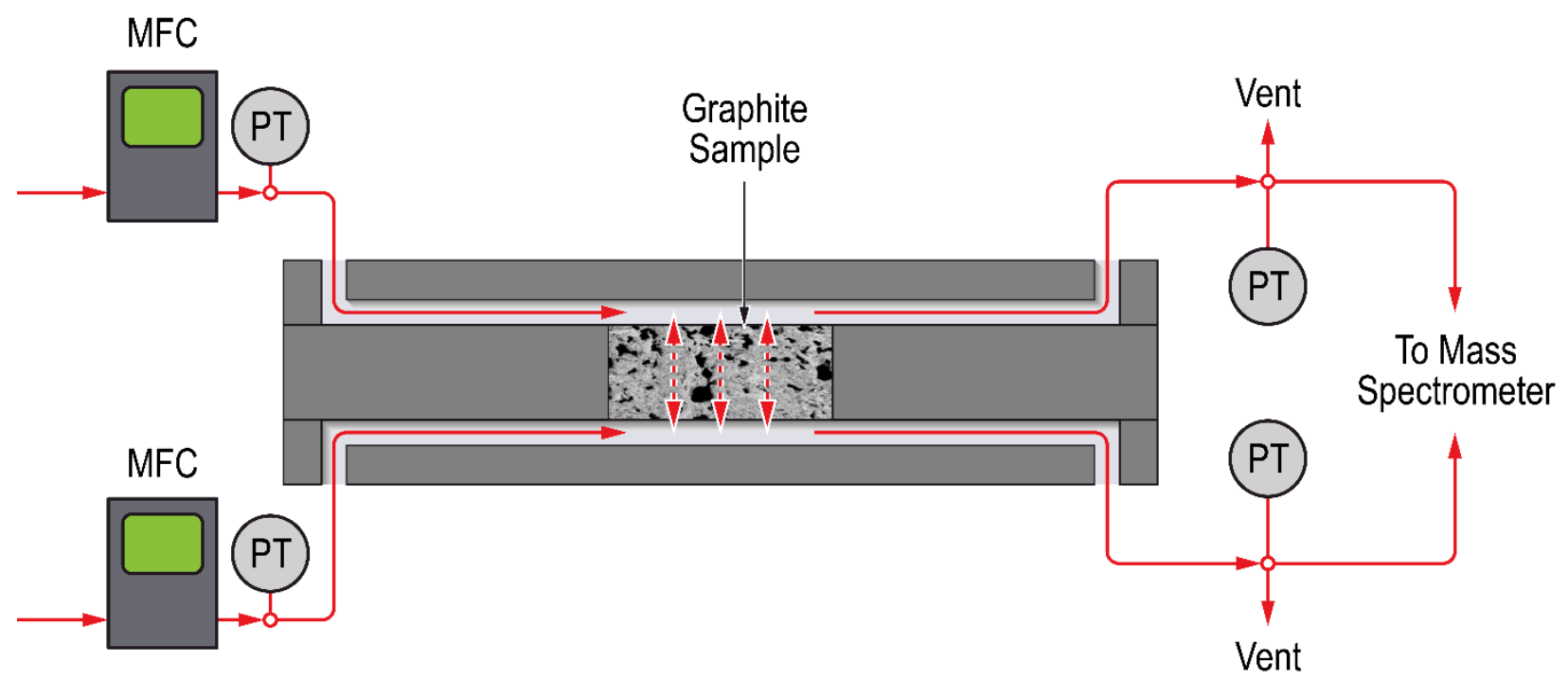

Figure 1. A flow diagram of the custom built Wicke-Kallenbach diffusion cell used for this work. MFC is the abbreviated form of mass-flow controller; PT is an abbreviated form of pressure transducer.

\subsection{Experimental procedure}

Each experiment was conducted according to the following procedure. Prior to beginning an experiment, vacuum grease was applied to the sides of a sample, and the sample was then placed into the sample slot within the center plate of the diffusion cell. Vacuum grease provided an excellent seal, with negligible contribution to measured mass transport. All surfaces other than the top and bottom faces were in intimate contact with the diffusion cell center plate. Once the diffusion cell was sealed, the system was purged (both channels) for at least an hour in $\mathrm{N}_{2}$. At the start of each experiment, gases were switched to UHP $\mathrm{N}_{2}$ and Ar on opposite sides of the cell with mass flow controllers (Alicat, U.S.A) set to $100 \mathrm{sccm}$. The mass flow controllers had an accuracy of $\pm 0.8 \mathrm{sccm}$ at the experimental set point. The flow rates used equated to a volume averaged gas velocity of $\sim 3.28 \mathrm{~cm} / \mathrm{s}$ and an approximate Reynold's number of 7.76 for $\mathrm{N}_{2}$. The channel height was $2 \mathrm{~mm}$.

All measurements were taken slightly above local ambient pressure, $\sim 87 \mathrm{kPa}$. High accuracy pressure transducers (Omega, USA), with an accuracy of $\pm 165 \mathrm{~Pa}$, located at positions indicated in Fig. 1, were used to continuously monitor the absolute pressure within the cell. Continual pressure monitoring ensured no measurable differential pressure existed across the cell throughout the course of the experiment. 
The primary goal of these experiments was to measure the flow of $\mathrm{Ar}$ and $\mathrm{N}_{2}$ across porous graphite samples. This was accomplished by measuring the outlet gas composition and solving a series of mass-balance equations. The outlet-gas compositions were measured throughout the experiment utilizing a HPR-20 QIC R\&D triple-filter mass spectrometer (Hiden Analytical, U.K) with a dual capillary inlet. Each capillary continuously pulled approximately $16 \mathrm{sccm}$ into the mass spectrometer. The continuous pull from each gas stream allowed for rapid measurements on either side of the diffusion cell without causing flow perturbation. All experiments were monitored until the flows across the graphite sample had established a pseudo-steady state, indicated visually by no change in measured signals of $\mathrm{Ar}$ and $\mathrm{N}_{2}$ with increasing time. Upon terminating the experiment, the cell was again continuously purged with $\mathrm{N}_{2}$.

\subsubsection{Mass spectrometer calibration}

The gas compositions of interest for the sample size and gas flows discussed in the previous sections fell within a range of approximately $500-5000 \mathrm{ppm}$. To ensure accurate measurements, while maintaining a fast measurement speed, a secondary electron multiplier (SEM) was used for detection. The SEM relative sensitivity of each component was checked and calibrated on a weekly basis to maintain accurate measurements over the course of this work.

A two point calibration was used to assess the SEM relative sensitivity of $\mathrm{Ar}$ and $\mathrm{N}_{2}$. A calibration gas flow rate of 1 and $10 \mathrm{sccm}$ was down-blended with $2000 \mathrm{sccm}$ of $\mathrm{Ar}$ or $\mathrm{N}_{2}$. This resulted in nominal minor-component compositions of 500 and $5000 \mathrm{ppm}$ respectively. The SEM relative sensitivity did not appear to change appreciably over the order of magnitude change in composition, confirming a high linear dynamic range over the range of interest.

\subsection{Mathematical methodology}

The materials balances used to determine the mass flow rates of $\mathrm{Ar}$ and $\mathrm{N}_{2}$ across the diffusion cell were fairly simple and are visually illustrated in Fig. 2. The mass balances are written in terms of one species (species may be arbitrarily assigned), and the subscript designators 1 and 2 represent side one and two of the cell, respectively. One assumption made below is the molar flow rates across the graphite plug, designated $n_{1 \rightarrow 2}$ and $n_{2 \rightarrow 1}$, are pure species flows of Ar or $\mathrm{N}_{2}$, and the flow is evenly dispersed across the entire cross-sectional area of the sample. 


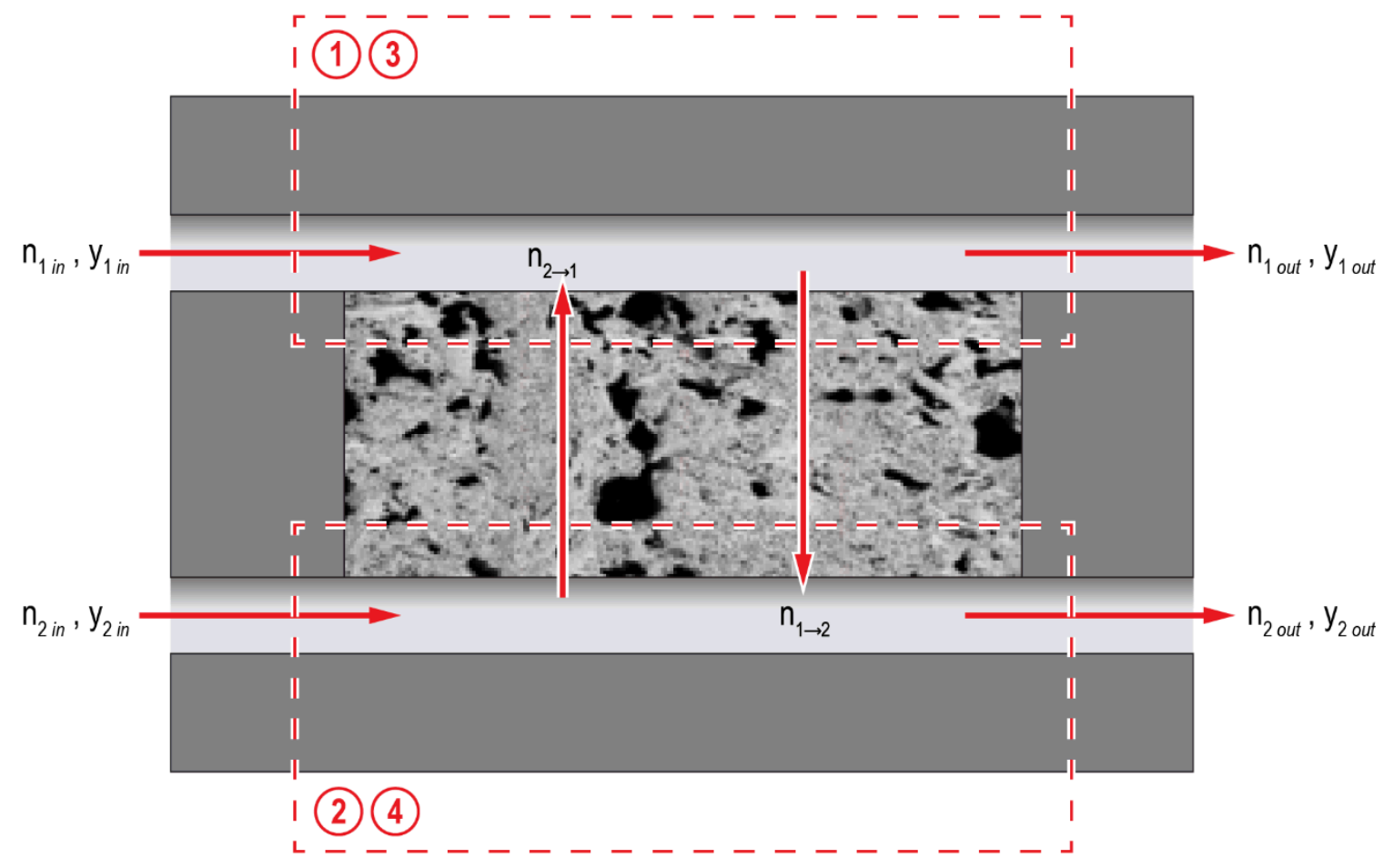

Figure 2. An illustration of the mass balances used to experimentally determine the flow rates of different gas species through a porous graphite sample. The information in this figure is represented mathematically by Equations 1 through 4 .

Total molar flow balances:

$n_{1_{\text {in }}}+n_{2 \rightarrow 1}=n_{1 \rightarrow 2}+n_{1_{\text {out }}}$

$n_{2_{\text {in }}}+n_{1 \rightarrow 2}=n_{2 \rightarrow 1}+n_{2_{\text {out }}}$

Species molar flow balances:

$n_{1_{\text {in }}} y_{1_{\text {in }}}=n_{1 \rightarrow 2}+n_{1_{\text {out }}} y_{1_{\text {out }}}$

$n_{2_{\text {in }}}\left(1-y_{2_{\text {in }}}\right)=n_{2 \rightarrow 1}+n_{2_{\text {out }}}\left(1-y_{2_{\text {out }}}\right)$

Mathematical combination of the above equations allow $n_{1 \rightarrow 2}$ and $n_{2 \rightarrow 1}$ to be solved for in terms of experimental knowns and measurable outlet gas compositions yielding

$\left[\begin{array}{ll}\left(1-y_{1_{\text {out }}}\right) & y_{1_{\text {out }}} \\ \left(1-y_{2_{\text {out }}}\right) & y_{2_{\text {out }}}\end{array}\right] \times\left[\begin{array}{l}n_{1 \rightarrow 2} \\ n_{2 \rightarrow 1}\end{array}\right]=\left[\begin{array}{l}n_{1_{\text {in }}}\left(y_{1_{\text {in }}}-y_{1_{\text {out }}}\right) \\ n_{2_{\text {in }}}\left(y_{2_{\text {out }}}-y_{2_{\text {in }}}\right)\end{array}\right]$ 
Eq. 5 was numerically solved utilizing MATLAB version 2016a for each measurement of the channel outlet compositions.

Upon solving for molar flows $n_{1 \rightarrow 2}$ and $n_{2 \rightarrow 1}$, the effective diffusion coefficients could be determined using Fick's first law. Here, Fick's first law is expressed in terms of the molar fluxes

of species A and B. Temperature, pressure, and the diffusion coefficient are considered constant with respect to $x$. This form of Fick's first law implicitly assumes gas transport occurs entirely by ordinary diffusion of gas through macropores and does not account for any contribution of Knudsen diffusion. This initial limiting assumption was based on primarily on work from the 1960 s in the U.K $[17,19,20,22,24,25,27]$.

$N_{A}=-D_{E f f_{A}} C \frac{\partial y_{A}}{\partial x}+y_{A}\left(N_{A}+N_{B}\right)$

$\frac{N_{A}}{N_{B}}=-\sqrt{\frac{M_{B}}{M_{A}}}$

Utilizing Graham's law of effusion, and solving Eq. 6 relative to the geometric and physical constraints of the system yields:

$D_{E f f_{A}}=\frac{\alpha L N_{A}}{C \ln \left(\frac{1-\alpha y_{1} \mid}{\left|1-\alpha y_{2}\right|}\right)}$

$\alpha=1-\sqrt{\frac{M_{A}}{M_{B}}}$

\section{Results}

A typical experimental measurement of outlet compositions, utilizing graphite grade NBG-17 sample 3 of 4, is shown in Fig. 3a. Similarly, the corresponding extracted diffusion coefficients for Ar and $\mathrm{N}_{2}$ are shown in Fig. 3b. While the effective diffusion coefficients do show variation with time before steady state, the values have little real physical meaning prior to steady state as the relation Eq. 8 is derived for steady-state conditions. A vertical gray line was added to Figs. 3a and $3 \mathrm{~b}$ to visually display the approximate time steady state is achieved. The time to achieve steady state is dependent upon the microstructure of the graphite and, therefore, varied to some degree from sample to sample and grade to grade. In general, steady state was achieved within an 
hour of beginning an experiment. The final steady-state effective diffusion coefficient of each sample is shown in Fig. 4. Basic summary statistics are given in Table 1 according to grade.
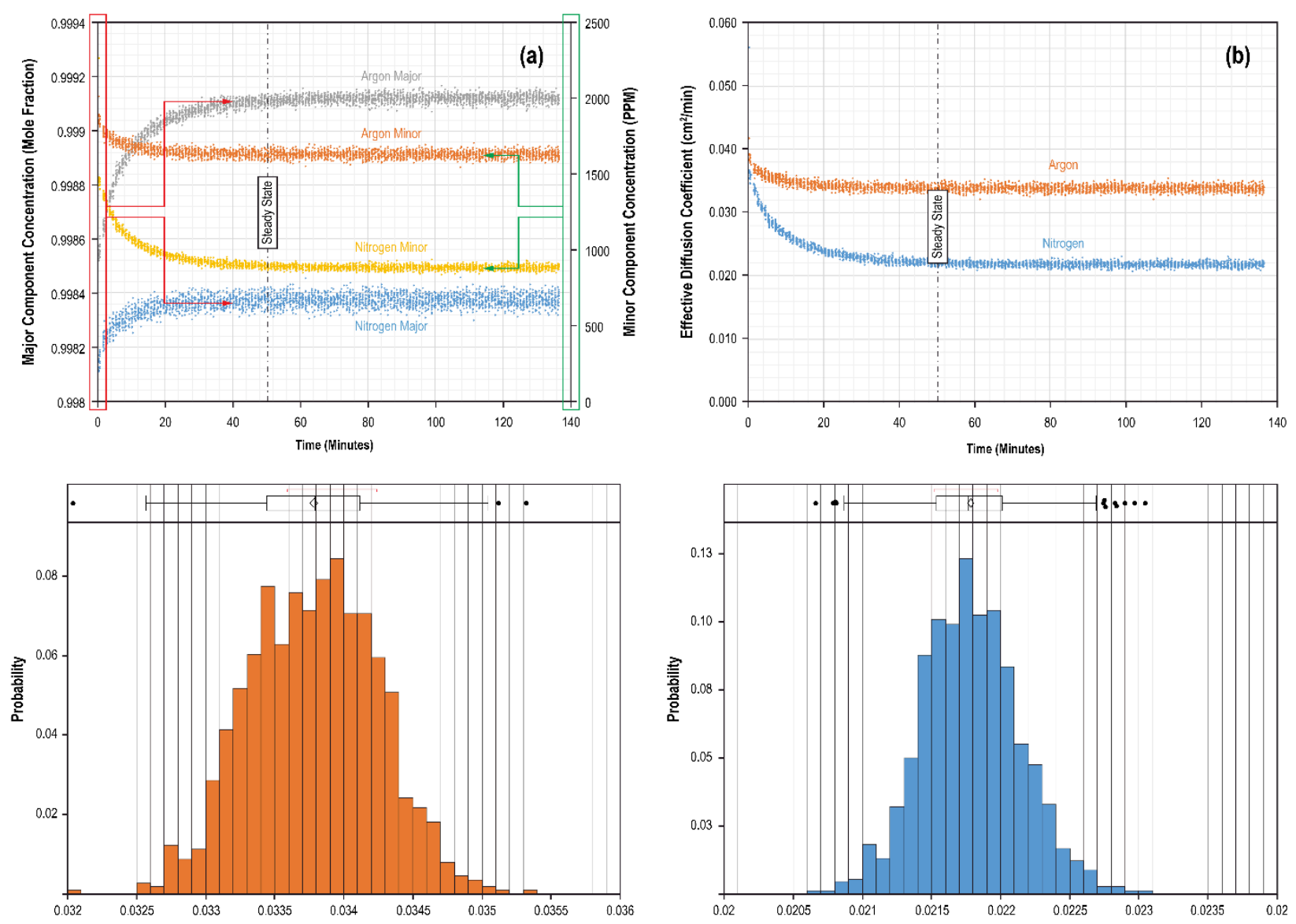

Figure 3. (a) Typical changes in composition observed over the course of a diffusion experiment. The particular data set shown belongs to the third of four samples tested for graphite grade NBG-17. (b) The mathematical manipulation of experimental data, shown in Fig. 3a, to extract the experimental effective diffusion coefficients. The small variation observed with time is likely due to small transient effects. The use of a steady-state relationship for effective diffusivity, Eq. 8, nullifies the use of data prior to the system reaching steady state. Histograms of effective diffusivity values for (c) $\mathrm{Ar}$ and (d) $\mathrm{N}_{2}$. These figures provide a statistical representation of the instantaneous diffusivity values and show the spread in data about the mean values. 


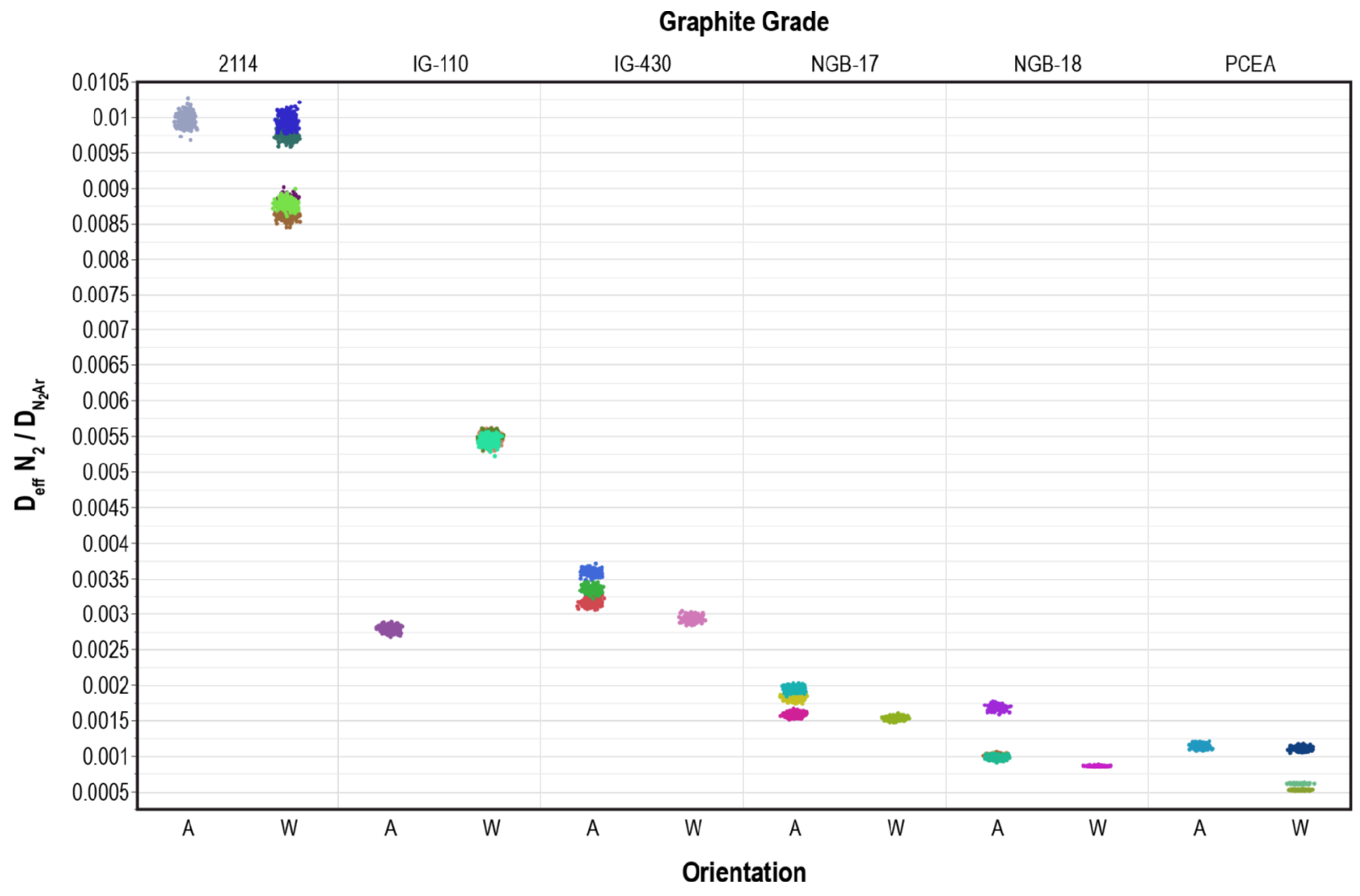

Figure 4. Effective diffusion coefficients for six nuclear grade graphites. Measurements are split into with (W), and against (A) gravity or extrusion directions, respective to the fabrication process. All values are normalized to the normal diffusion coefficients for an $\mathrm{Ar} / \mathrm{N}_{2}$ mixture at room temperature and $87 \mathrm{kPa}$. Additional details regarding the calculation of normal diffusion coefficients can be found in the supplemental material. 
Table 2. Effective diffusion coefficients for the six nuclear graphite grades investigated. Values are normalized to the bulk diffusion coefficients for an $\mathrm{Ar} / \mathrm{N}_{2}$ mixture at room temperature and $87 \mathrm{kPa}$ to provide a convenient means of scaling the experimental values to higher temperatures (and pressures) of interest. Additional details regarding the calculation of normal diffusion coefficients can be found in the supplemental material.

\begin{tabular}{|c|c|c|c|c|c|c|c|}
\hline & & & & GRADE & & & \\
\hline & $\times 10^{-3}$ & 2114 & IG-110 & IG-430 & NBG-17 & NBG-18 & PCEA \\
\hline$\underline{D_{e f f N 2}}$ & $\mu$ & 9.30 & 4.62 & 3.26 & 1.70 & 1.10 & 0.87 \\
\hline$D_{N_{2} A r}$ & $\boldsymbol{\sigma}$ & 0.60 & 1.24 & 0.23 & 0.17 & 0.28 & 0.28 \\
\hline & Min & 8.45 & 2.68 & 2.84 & 1.47 & 0.85 & 0.51 \\
\hline & Max & 10.27 & 5.62 & 3.72 & 2.02 & 1.77 & 1.21 \\
\hline$\underline{D_{e f f A r}}$ & $\mu$ & 10.25 & 5.18 & 3.72 & 2.29 & 1.13 & 1.37 \\
\hline$A$ & $\sigma$ & 0.57 & 1.14 & 0.23 & 0.12 & 0.13 & 0.49 \\
\hline & Min & 9.13 & 3.41 & 3.24 & 2.08 & 0.87 & 0.60 \\
\hline & $\operatorname{Max}$ & 11.02 & 6.15 & 4.11 & 2.54 & 1.30 & 2.16 \\
\hline
\end{tabular}

\section{Discussion}

\subsection{Comparison of diffusion coefficient magnitude}

As introduced previously, a limited number of studies measure gas-diffusion coefficients for nuclear-grade graphites. Of the studies known to the authors, a majority were conducted in the 1960s by the United Kingdom's Atomic Energy Research Establishment on British nucleargraphite grades. British grades, such as PGA, were designated as medium grain with a nominal grain size of $0.8 \mathrm{~mm}$ (similar to PCEA and NBG-17); however, they were appreciably lower in density than their current generation counterparts. PGA has a density of approximately $1.7 \mathrm{~g} / \mathrm{cm}^{3}$ compared to more modern medium-grain grades with densities in the range of $1.8-1.85 \mathrm{~g} / \mathrm{cm}^{3}$ 
[28]. Several of the British nuclear grades were described as large-pore graphites by Hewitt et al. [25]. The values found in several of these studies are provided in Table 3.

Table 3. Summary description of a number of historic effective-diffusion measurements of various carbon and graphite materials. Most of the information tabulated here is related to graphite considered for British nuclear graphite (BNG) grades.

\begin{tabular}{|c|c|c|c|c|}
\hline Graphite & $\mathbf{D}_{\text {eff }} / \mathbf{D}_{\mathrm{AB}}$ & Gas & Note & Reference \\
\hline$B N G^{*}$ & 0.02 & Variety & & {$[25]^{\star}$} \\
\hline$B N G^{*}$ & $0.007-0.01$ & $\mathrm{O}_{2} / \mathrm{N}_{2}$ & $\begin{array}{l}\text { Predominantly controlled by normal } \\
\text { diffusion }\end{array}$ & {$[25]^{\star}$} \\
\hline$B N G^{*}$ & 0.0088 & $\mathrm{O}_{2} / \mathrm{N}_{2}$ & $\begin{array}{l}\text { Significant variation in measurement } \\
\text { relative to grades extrusion direction }\end{array}$ & [16] \\
\hline$B N G^{*}$ & 0.008 & $\mathrm{O}_{2} / \mathrm{N}_{2}$ & $\begin{array}{l}\text { Measured value reached } 0.023 \text { at } \sim 7 \% \\
\text { mass loss. }\end{array}$ & {$[25]^{\star}$} \\
\hline$B N G^{*}$ & $0.007-0.013$ & $\begin{array}{l}\mathrm{O}_{2} / \mathrm{N}_{2} \& \\
\mathrm{~N}_{2} \mathrm{O} / \mathrm{N}_{2}\end{array}$ & & {$[25]$} \\
\hline$P G A$ & 0.015 & $\mathrm{CO}_{2} / \mathrm{He}$ & Measured at $1000^{\circ} \mathrm{C}$ and $1 \mathrm{~atm}$ & [27] \\
\hline $\begin{array}{l}\text { Ungraphitized } \\
\text { Carbons }\end{array}$ & $\begin{array}{c}0.0214 \\
0.017\end{array}$ & $\mathrm{O}_{2} / \mathrm{N}_{2}$ & $\begin{array}{l}\text { Measured indirectly from oxidation } \\
\text { measurements with analytical solution }\end{array}$ & [19] \\
\hline Pile Grade & $\sim 0.008-0.009$ & $\mathrm{O}_{2} / \mathrm{N}_{2}$ & $\begin{array}{l}\text { Slight composition dependence } \\
\text { observed }\end{array}$ & [24] \\
\hline Pile Grade & $0.008-0.015$ & $\mathrm{O}_{2} / \mathrm{N}_{2}$ & $\begin{array}{l}\text { Measured indirectly from oxidation } \\
\text { measurements with analytical solution }\end{array}$ & {$[22]$} \\
\hline $\begin{array}{c}\text { National Carbon } \\
\text { Co. 'AGOT' CS } \\
\text { Grade }\end{array}$ & $0.0085-0.0096$ & $\mathrm{He} / \mathrm{Ar}$ & Large-pored & [17] \\
\hline PBMR A3-27 Matrix & 0.001 & ? & $\begin{array}{l}\text { Matrix material is not fully } \\
\text { graphitized }\end{array}$ & {$[29]^{\star}$} \\
\hline
\end{tabular}

* Unpublished, but described in cited reference

$\star$ ' $B N G$ ' is used here to refer to a graphite of interest to U.K nuclear reactors when no additional information was easily obtained from the references. In some cases these may have been different graphite trial batches for Magnox reactors.

With the exception of superfine grade 2114 , the grades examined in this study have effective diffusivities approximately two times to a full order of magnitude lower than historical grades. The work of Hinssen et al. on PBMR A3 matrix agrees reasonably well with the medium grain 
grades from this study, but this is likely fortuitous because the matrix material should have a significantly different pore structure than these nuclear grades. These differences are strongly tied to distinctly different initial materials and fabrication processes. Furthermore, while the A3 matrix is heat-treated at high temperatures [30-32], it does not undergo graphitization at 2600$3000^{\circ} \mathrm{C}$, as does a typical synthetic graphite.

\subsection{Diffusion coefficient correlations or lack thereof}

\subsubsection{No observed correlation with graphite processing direction}

A thorough study conducted by Hewitt et al. showed significant variation in the diffusion coefficient of an extruded British nuclear grade along the cross-section of a graphite block [16]. Significant differences were measured with sample orientation relative to the extrusion axis of the grade. Overall, the mean value of $\frac{D_{E f f}}{D_{A B}}$ observed was 0.0088 with a standard deviation of 0.0021 ( $\sim 24 \%$ of the mean).

Based on Hewitt's thorough study it was postulated that some directional variation would be observed in at least the near-isotropic grades NBG-17, NBG-18, and PCEA [16]. No such variation was observed within the statistical certainty of the small sample population of each grade. From Fig. 4, a small directional dependence may be plausible, but a significantly larger sample population is needed to confirm this with any reasonable certainty. These results qualitatively suggest that variability and anisotropy are significantly reduced in current grades compared to historic grades, even for modern extruded grades such as PCEA. The grade IG-110 is one possible exception; however, given the grade's isotropic designation [33], the observed difference with direction is better explained by variation in porosity or density rather than material anisotropy, as discussed in the following section.

\subsubsection{Correlation with graphite porosity}

Quite often in the greater body of literature on gas transport through porous materials, an attempt is made to correlate the effective diffusion coefficient with a relationship such as

$\frac{D_{E f f}}{D_{A B}}=f=\frac{\phi \sigma}{\tau^{2}}$

where $\phi$ represents the open porosity of the material and the corresponding reduction in the effective gas transport cross-section, $\sigma$ represents a constriction factor accounting for changing 
pore cross-sectional area, and $\tau$ represents the geodesic tortuosity of the pore structure, which physically represents the increased path length a gas molecule must travel compared to the sample thickness over which a measurement is made. Figure 5a, plots the left hand side of Eq. 9 against estimates of total porosity, estimated from density, for each sample.
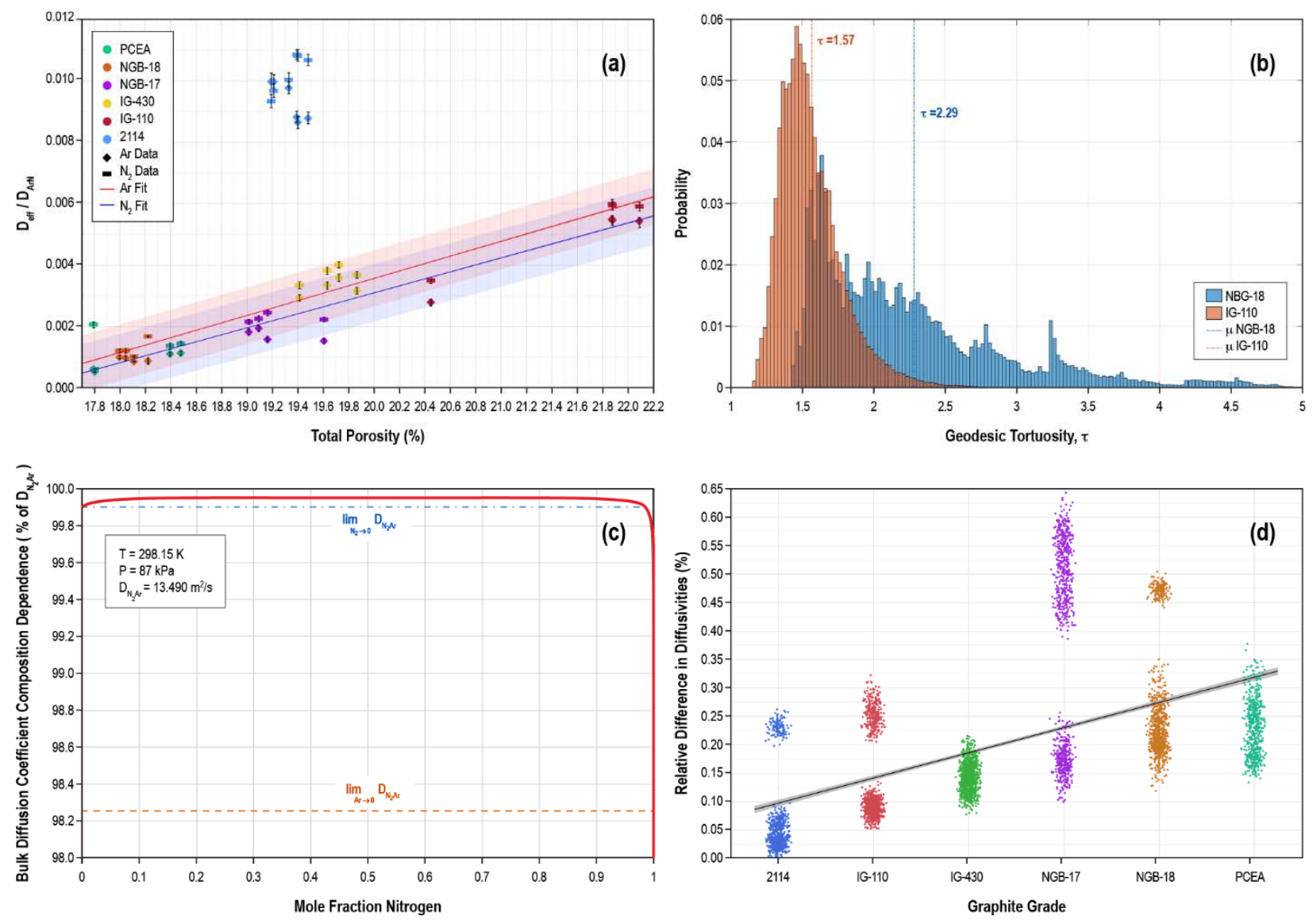

Figure 5. (a) $\frac{D_{E f f}}{D_{A B}}$ plotted against estimated total porosity for Ar and N2. Estimated total porosity was calculated using each sample's measured density and an estimated theoretical density of $2.253 \mathrm{~g} / \mathrm{cm}^{3}$. (b) shows the volumetric distribution of geodesic tortuosity within graphite grades IG-110 and NBG-18 measured from X-ray tomographic data. Additional information can be found in the supplemental material. (c) shows a second order approximation of the normal diffusion coefficient for an $\mathrm{Ar}-\mathrm{N}_{2}$ binary mixture. This approximation takes into account composition. Additional information regarding the calculation may be found in the supplemental material. (d) shows the relative difference between measured values of $\frac{D_{E f f}}{D_{A B}}$ for $\mathrm{Ar}$ and $\mathrm{N}_{2}$. It should be noted that the observed trends are qualitatively reasonable; however, the actual values 
may have a significant degree of uncertainty. Significant mathematical manipulation is needed to obtain the desired values from the mass spectrometer output and measurement uncertainty is propagated and increased.

Three features of Fig. 5a are worthy of further discussion. The first two are discussed here, and the third will be discussed in Section 4.3. First, the large variation observed in Fig. 4 for IG-110 in the A direction (see Section 4.2.1) appears to be reasonably accounted for by considering the difference in the estimated total porosity of the samples. A second observation is the strong linear correlation for all measured grades, with the obvious exception of 2114, with total porosity.

Pertinent information regarding the linear regressions is given in Table 4. The linear trend from Fig. 5a also appears to extend back to historic lower-density U.K grades such as PGA. Using a porosity of 0.245 (density of $1.7 \mathrm{~g} / \mathrm{cm}^{3}[28]$ and an estimated theoretical density of $2.253 \mathrm{~g} / \mathrm{cm}^{3}$ ), the estimated value of $\frac{D_{E f f}}{D_{A B}}$ for PGA is 0.0083 and 0.0091 based on $\mathrm{N}_{2}$ and Ar, respectively. These values appear to be in good agreement with the value of 0.0088 listed for PGA in Table 3 [27].

Table 4. Slope, intercept, and $\mathrm{R}^{2}$ values from the linear regression of $\frac{D_{E f f}}{D_{A B}}$ for $\mathrm{Ar}$ and $\mathrm{N}_{2}$ with estimated total porosity. It should be noted that the total porosity should be used in a fractional form to produce the correct value of $\frac{D_{E f f}}{D_{A B}}$. The values listed for slope and intercept are the mean values and their respective, two-sided, $95 \%$ confidence intervals.

\begin{tabular}{c|ccc}
\multicolumn{1}{c}{ Slope } & Intercept & $\mathbf{R}^{\mathbf{2}}$ \\
\hline $\mathbf{A r}$ & $(1.207 \pm 0.011) \mathrm{E}-01$ & $(-2.057 \pm 0.021) \mathrm{E}-02$ & 0.92 \\
$\mathbf{N 2}$ & $(1.138 \pm 0.011) \mathrm{E}-01$ & $(-1.966 \pm 0.021) \mathrm{E}-02$ & 0.91
\end{tabular}

While the degree of correlation between $\frac{D_{E f f}}{D_{A B}}$ and total porosity appear to be quite high, this correlation is somewhat superficial given the large deviation of 2114 experimental values from the linear fit. If the correlation were purely due to variation in total porosity, the ratio of effective diffusivities between two grades should be approximately equal to the ratio of porosities of the same respective grades (Eq. 10). This relationship however does not hold true. 
$\frac{D_{E f f_{1}}}{D_{E f f_{2}}} \cong \frac{\phi_{1}}{\phi_{2}}$

For IG-110 and NBG-18 the ratio of effective diffusivities for $\mathrm{N}_{2}$ is approximately 4.2 , based on Table 1. The corresponding ratio of nominal total porosity, however, is approximately 1.04. Even after utilizing measurements of open porosity for NBG-18 and IG-110 (8.19\% and 12.72\%, respectively [32]), the porosity ratio is no greater than 1.55 . This comparison implies that there are additional factors contributing to the effective diffusivity that scale to some degree with porosity. While the effective geodesic tortuosity and, to a lesser degree, variation in pore diameter along a pores length, $\sigma$, will undoubtable play some role, these two factors alone do not fully explain the observed differences between grades.

An example is given here to reinforce the previous assertion. This example considers super-finegrain grades IG-110 and 2114, as well as medium-grain grade NBG-18. From an elegant explicit relation derived by Eugene Peterson [34], $\sigma$ should take on a value no smaller than $\sim 0.333$ in the most extreme cases. Using this value for, $\sigma_{\operatorname{Min}}$ and open porosity values from [32], an approximation of the extreme minimum values for $\tau$ can be made Eq. 11, a rearrangement of Eq. 9.

$\tau_{\text {Min }}=\sqrt{\frac{\phi \sigma_{\operatorname{Min}} D_{A B}}{D_{E f f}}}$

The corresponding minimum values for $\tau_{\text {Min }}$ are 2.87, 2.00, and 5.03 for IG-110, 2114, and NBG18, respectively. A first observation to note from this example is that these values appear significantly higher than one may expect from physical 3-D measurements of porosity in these grades. Fig. 5b shows the distribution of geodesic tortuosity within IG-110 and NBG-18 extracted from multiple x-ray computed tomography (CT) scans and weighted volumetrically. The corresponding mean values of $\tau$ are approximately 1.57 and 2.29 for IG-110 and NBG-18, respectively. A second observation to note from this example is the significant difference between IG-110 and 2114 values for $\tau$ given their high degree of similarity in terms of forming process and filler-particle size. Filler-particle and flour size distribution plays an important role in the pore-size distribution of graphite [35]. All else being equal, the tortuosity for these two grades should be very similar, yet the calculated values vary significantly. $\tau$ and $\sigma$ alone cannot explain higher-than-predicted geodesic tortuosity for IG-110 and NBG-18, nor can they account 
for the significant difference between $\tau_{\text {Min }}$ values estimated for IG-110 and 2114, despite their similarities.

\subsection{Contribution of Knudsen diffusion}

As discussed in the previous section, differences in the open porosity, geodesic tortuosity, and constriction factors for each grade do not sufficiently explain the linear trend from Fig. 5a, nor the large deviation of 2114 from the other grades of similar density. A third observation from Fig. 5a, however, may provide a more reasonable explanation. Fig. 5a shows a statistically significant difference between the measured effective diffusivities for Ar and $\mathrm{N}_{2}$. The difference

in experimental values for $\mathrm{Ar}$ and $\mathrm{N}_{2}$ suggest that Knudsen diffusion can contribute significantly to the measured rates of mass transport.

Returning briefly to ideas discussed in Section 2.3.1, the assumption was made that all gas transport occurs via ordinary diffusion. If this assumption were valid, there should be no measureable difference in the diffusion coefficients for $\mathrm{Ar}$ and $\mathrm{N}_{2}$, as normal diffusion coefficients are generally considered independent of gas composition for a given gas pair. Even using a more rigorous approximation of diffusion coefficients, such as the Chapman-Enskog theory, and taking into account a small composition dependence, the effective diffusivities should be within $2 \%$ of one another over the entire composition range for $\mathrm{Ar}$ and $\mathrm{N}_{2}$ (Fig. 5c) [36-38]. Conversely, Knudsen diffusion coefficients depend on the identity of the diffusing molecules; consequently, as the difference between the measured effective diffusivities of Ar and $\mathrm{N}_{2}$ become larger, Knudsen diffusion likely plays a more significant role in the transport of gas through the pore structure.

Figure $5 \mathrm{~d}$ plots the difference between Ar and $\mathrm{N}_{2}$ measured effective diffusivity values and normalizes the difference to the effective diffusivity of $\mathrm{N}_{2}$. In essence, this figure shows the magnitude of the observed differences in the Ar and $\mathrm{N}_{2}$ diffusion rates by grade. Comparing the $2 \%$ variation from compositional dependence to Fig. $5 \mathrm{~d}$, all grades, with the exception of 2114 , show significantly higher differences in the measured effective diffusivities for $\mathrm{Ar}$ and $\mathrm{N}_{2}$. Given the absence of any significant composition dependence for normal diffusion, an increase in the relative difference between $\mathrm{Ar}$ and $\mathrm{N}_{2}$ diffusivities should indicate an increasing contribution of Knudsen diffusion to the measured effective diffusion coefficient. 


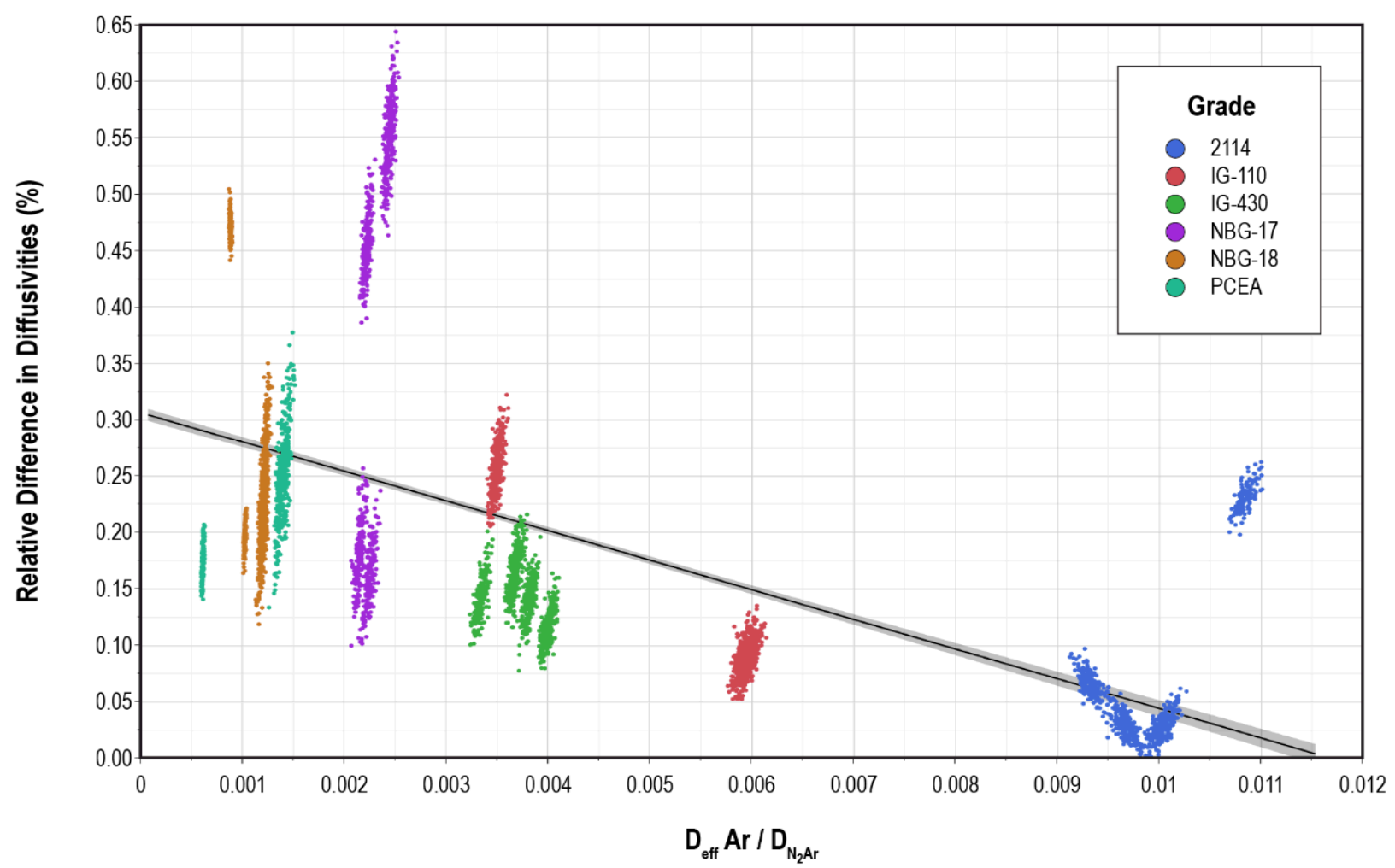

Figure 6. The relative difference between measured values of $\mathrm{Ar}$ and $\mathrm{N}_{2}$ diffusivity measurements (see Fig. 5d) for various grades plotted against the effective diffusivity measured for Ar. The plot shows the general trend of decreasing difference between diffusivity values for Ar and $\mathrm{N}_{2}$ with increasing measured value of effective diffusivity.

Knudsen diffusion becomes an appreciable transport process as the mean free path of a gas molecule approaches the diameter of the pore through which transport occurs. Lang et al. provides an excellent comprehensive review of the experimental and theoretical subject matter for the interested reader [39]. For the experimental conditions described in Section 2.3, the mean free paths of $\mathrm{Ar}$ and $\mathrm{N}_{2}$ are approximately $80 \mathrm{~nm}$. For a pore of identical diameter, the Knudsen diffusion coefficient for Ar is approximately $7 \mathrm{~cm}^{2} / \mathrm{min}$ compared to a value for the ordinary diffusion coefficient of nearly $12 \mathrm{~cm}^{2} / \mathrm{min}$. These approximations suggest that as Knudsen diffusion becomes more important for a particular grade of graphite, the effective diffusion coefficient should decrease. If

1. Greater relative differences in measured diffusion coefficients indicate greater Knudsen diffusion contributions, and

2. Greater Knudsen diffusion contributions result in lower effective diffusion coefficients, 
then a comparison of the relative differences from Fig. $5 \mathrm{~d}$ and the measured diffusivity should show a negative correlation. Figure 6 plots the differences in $\mathrm{Ar}$ and $\mathrm{N}_{2}$ effective diffusivities from Fig. 5d against the Ar effective diffusivity measurements for each sample. While there is significant scatter, the figure shows the same negative correlation. The grades in which Knudsen diffusion plays a more significant role (suggested by the greater difference in Ar and $\mathrm{N}_{2}$ diffusivity) have lower effective diffusivities.

\subsubsection{Influence of pore-size distribution on diffusion}

The increased diffusion rate observed in 2114 compared to the other fine-grain grades of similar density, as well as the lower overall effective diffusivities of the medium-grain grades may reasonably be explained by examination of the pore-size distributions. Multiple studies have determined pore-size, more appropriately pore entrance size, distributions for nuclear grade graphites using mercury porosimetry [32, 40-44]. Many of the modern grades examined have a bimodal pore size distribution, with porosity falling in both the macropore ( $>50 \mathrm{~nm}$ diameter) and mesopore $(2 \mathrm{~nm}<$ diameter $<50 \mathrm{~nm}$ ) range [45]. In the macropore range, most of the grades have porosity with an equivalent pore diameter on the order of $1 \mu \mathrm{m}$ or greater. The mesopores are typically in the range of $10 \mathrm{~nm}$. While the size of the macroporosity is highly correlated with the filler-particle and flour-size distribution, the size and volume of mesoporosity is likely much more dependent upon the binder materials and any materials used for further densification or post-processing [35].

Knudsen diffusion is only a pertinent consideration for the mesoporosity within nuclear graphite. Recent mercury porosimetry work has, in general, shown medium grain grades tend to have a larger volume of mesoporosity than the fine grain grades [32, 41-43]. Given the larger volume of mesoporosity and the lower total pore volumes of medium-grain grades, mesoporosity represents a larger fraction of the total pore volume and likely contributes more substantially to the overall diffusion rate through these grades. Likewise, the smaller mesopore volumes and higher total pore volumes of the finer-grain grades make Knudsen diffusion less important, volumetrically, to the diffusion process [32, 41-43].

To explain 2114's significantly higher diffusion rate, we hypothesize that the binder used in production does not yield a significant volume of mesopores or, post-processing has been used to seal, fill, or close the mesoporosity. If this hypothesis is correct, mesopores are inaccessible 
(closed porosity) or do not exist for gas transport in 2114, and transport primarily occurs via normal diffusion. This, in turn, results in a higher overall measured diffusion coefficient compared to a similar grade, such as IG-430, with accessible mesopores.

\subsubsection{Higher diffusion rates for argon than nitrogen}

From classic kinetic theory for dilute gases, the arithmetic mean velocity of a particle ensemble with a Boltzmann distribution of energy is

$\left\langle v_{A}\right\rangle=\sqrt{\frac{8 k T}{\pi M_{A}}}$

From Eq. 12, $\mathrm{N}_{2}$ should have an arithmetic mean velocity approximately 1.194 time higher than Ar. The Knudsen diffusion coefficient is directly proportional to the mean velocity of a gas molecule and, thus, any differences in the measured diffusion coefficients for $\mathrm{Ar}$ and $\mathrm{N}_{2}$ should show $\mathrm{N}_{2}$ as having the higher diffusivity. This is not observed experimentally. With the exception of some of the 2114 measurements, the effective diffusivity of Ar is always higher than $\mathrm{N}_{2}$. For grades such as NBG-18 and PCEA, the relative ratio of Ar to $\mathrm{N}_{2}$ diffusivity approaches a value of 0.8 (Fig. 5d). While the measured values will be somewhat dependent on the individual sample's pore-size distribution and the crystallographic orientation along the pore walls, the underlying cause of this apparent discrepancy is likely related to the quadrupole moment of $\mathrm{N}_{2}$.

$\mathrm{N}_{2}$ is generally considered inert in the thermal oxidation of graphite. Its quadrupole moment, however, allows it to interact more with the carbon surface (especially at surfaces with $\{100\}$ and $\{1 \overline{1} 0\}$ crystallographic orientations) than an inert, spherical, electrically symmetric argon atom. The increased interaction of $\mathrm{N}_{2}$ with carbon surfaces, even at room temperature, will in turn slow its progression through a pore. While $\mathrm{N}_{2}$ will interact with carbon surfaces of all pores, this effective decrease in the diffusion rate will only be observed in pores where the number of collisions between gas molecules and the pore wall is significant relative to the total number of collisions (gas-gas and gas-pore wall). In other words, only in pores where Knudsen diffusion is predominant. 


\subsubsection{Importance of quantifying Knudsen contribution}

Returning briefly to Eq. 9, the experimental values, quoted as $\frac{D_{E f f}}{D_{A B}}$, represent a first but crude approximation of the a structural factor for each grade. Ignoring the Knudsen contribution to diffusion, the structural factor for each grade could be used to estimate the effective diffusivity of different gas mixtures for a specific graphite grade. For example under this idealized condition, one could use the structural factors to estimate the effective diffusivity of molecular oxygen in helium for various grades. Section 4.3, however, has focused on justifying the contribution of Knudsen diffusion to room-temperature gas transport within the examined graphite grades. Oxidation pertinent to nuclear reactors, however, has significantly different gas mixtures composed of varying amounts of $\mathrm{He}, \mathrm{N}_{2}, \mathrm{O}_{2}, \mathrm{H}_{2} \mathrm{O}, \mathrm{CO}$, and $\mathrm{CO}_{2}$ and also takes place at significantly higher temperatures.

As described in Section 4.3.1, many of the modern nuclear graphites discussed here are bimodal, with a significant fraction of their porosity falling within the normal diffusion range, and the remainder falling well within the Knudsen diffusion regime. Given a bimodal distribution, and assuming the transport through both pore regimes takes place in parallel, a simplified representation of the contributions of normal and Knudsen diffusion to the effective diffusivity may be given as

$D_{E f f_{A}}=\frac{D_{A B} f_{N}}{1-\alpha y_{A}}+D_{K_{A}} f_{K}$

where subscript $A$ designates species in a binary gas mixture of $A$ and $B, D_{K_{A}}$ represents the Knudsen diffusion coefficient for $A$, and $f_{N}$ and $f_{K}$ represent structural factors (Eq. 10) for pores within normal and Knudsen regimes, respectively. The remaining factors have identical meanings to those defined in previous equations. Using this more realistic description, Eq. 13, two structural factors are needed to generally predict the effective diffusivity of gas mixtures as the Knudsen term is species dependent.

Shifting to the effects of temperature, at the higher temperatures relevant to oxidation, the importance of normal diffusion and Knudsen diffusion may differ from room temperature due to two competing factors. The first is the temperature dependence of the respective diffusion coefficients $D_{A B} \propto T^{3 / 2}$ and $D_{K} \propto T^{1 / 2}$. At $700^{\circ} \mathrm{C}$, the ratio of normal to Knudsen diffusion 
should be over 3.25 times greater than the same ratio at room temperature. Considering this factor alone, the normal diffusion component should become more dominant at relevant reactor temperatures. A second factor to consider, however, is a significant increase in the mean free path of a gas molecule. At room temperature, the mean free path is approximately $80 \mathrm{~nm}$ for $\mathrm{Ar}$ and $\mathrm{N}_{2}$, while at $700^{\circ} \mathrm{C}$, the mean free path is closer to $270 \mathrm{~nm}$. The larger mean free path increases the average diameter of pores influenced by Knudsen diffusion. For many of the medium-grain grades discussed here, the increase in mean free path will likely be insignificant, while for the finer grain grades discussed here, the influence may be significant. While the contributions of Knudsen diffusion have not been directly quantified here, future work must consider this in order to accurately correlate room temperature measurements to relevant oxidation temperatures.

\section{Conclusions}

Understanding the rate of gaseous mass transport within porous nuclear graphite is an important factor in predicting the observed rate of oxidation for graphite. In addition, oxidation damage will influence mechanical, physical, and thermal properties of graphite. The overall effect of oxidation on material properties depends upon the total amount of oxidation, but also on the depth and gradient of the damage that occurs. Transport measurements have been made for historic grades, but very few measurements are available for modern nuclear graphites with different microstructures. This work provides an initial assessment of gas-transport rates for six modern fine- and medium-grain nuclear-graphite grades through the experimental measurement of effective diffusion coefficients.

Five of the grades examined had effective diffusion coefficients between two and ten times lower than historic nuclear grades. The lower effective diffusivities of these modern grades can be attributed to their lower total porosities, but also to Knudsen diffusion playing an appreciable role in the observed rates. Knudsen diffusion does not play a significant role in measured diffusion rates of historic grades. Its importance here is hypothesized to be a combination of lower total porosities and a larger fraction of the total porosity existing in the mesopore range. The remaining grade had an effective diffusion coefficient comparable to historic grades. It was speculated that this grade does not possess a significant fraction of mesopores due to the binder used during fabrication or post-processing efforts to fill or seal the porosity. 
In order to properly extrapolate the room temperature effective diffusion coefficients to conditions relevant for graphite oxidation, the normal and Knudsen contributions to the overall rate need to be quantified. Additional efforts are currently underway to quantify individual contributions of normal and Knudsen diffusion through transport measurement with multiple gas pairs of different kinematic diameters and molecular weights.

\section{Acknowledgments}

This work was performed by Battelle Energy Alliance, LLC under the DOE Idaho Operations Contract DE-AC07-05ID14517.

\section{References}

[1] Petti D, Hill R, Gehin J, Gougar H, Strydom G, Heidet F, et al. Advanced Demonstration and Test Reactor Options Study. External Report: Idaho National Laboratory; 2016 July 2015. Report No.: INL/EXT-16-37867.

[2] Kadak AC. The Status of the US High-Temperature Gas Reactors. Engineering. 2016;2(1):119-23.

[3] Phillip Finck MS, George Griffith, Steve Herring, Craig Welling, Steven Reeves. Advanced Teactor Concepts Technical Review Panel Public Report Evaluation Evaluation and Recommendations for Future R\&D on Seven Advanced Reactor Concepts, Conducted March through June 2014: Department of Energy; 2014.

[4] Lee JJ, Ghosh TK, Loyalka SK. Oxidation rate of nuclear-grade graphite NBG-18 in the kinetic regime for VHTR air ingress accident scenarios. Journal of Nuclear Materials. 2013;438(1-3):77-87.

[5] Lee JJ, Ghosh TK, Loyalka SK. Oxidation rate of nuclear-grade graphite IG-110 in the kinetic regime for VHTR air ingress accident scenarios. Journal of Nuclear Materials. 2014;446(1-3):38-48.

[6] Yang H, Eun H, Lee D, Jung C, Lee K. Analysis of combustion kinetics of powdered nuclear graphite by using a nonisothermal thermogravimetric method. Journal of Nuclear Science and Technology. 2006;43:4.

[7] El-Genk MS, Tournier J-MP. Development and validation of a model for the chemical kinetics of graphite oxidation. Journal of Nuclear Materials. 2011;411(1-3):193-207.

[8] El-Genk MS, Tournier J-MP. Comparison of oxidation model predictions with gasification data of IG-110, IG-430 and NBG-25 nuclear graphite. Journal of Nuclear Materials. 2012;420(13):141-58.

[9] El-Genk MS, Tournier J-MP, Contescu CI. Chemical kinetics parameters and model validation for the gasification of PCEA nuclear graphite. Journal of Nuclear Materials. 2014;444(1-3):112-28.

[10] Chi S-H, Kim G-C. Comparison of the oxidation rate and degree of graphitization of selected IG and NBG nuclear graphite grades. Journal of Nuclear Materials. 2008;381(1-2):9-14. [11] Kane JJ, Karthik C, Ubic R, Windes WE, Butt DP. An oxygen transfer model for high purity graphite oxidation. Carbon. 2013;59:49-64.

[12] Contescu CI, Guldan T, Wang P, Burchell TD. The effect of microstructure on air oxidation resistance of nuclear graphite. Carbon. 2012;50(9):3354-66. 
[13] Contescu CI, Mee RW, Wang P, Romanova AV, Burchell TD. Oxidation of PCEA nuclear graphite by low water concentrations in helium. Journal of Nuclear Materials. 2014;453(13):225-32.

[14] Kim ES, No HC. Experimental study on the oxidation of nuclear graphite and development of an oxidation model. Journal of Nuclear Materials. 2006;349(1-2):182-94.

[15] Mays TJ, University of B. Gaseous diffusion and pore structure in nuclear graphites: University of Bath; 1988.

[16] Hewitt GF, Morgan JR. The Diffusion of Oxygen in Nitrogen in Pores of Graphite. In: Stanford EG, Fearon JH, McGonnagle WJ, eds. Progress in Applied Materials Research. London: Temple Press Books Ltd 1964.

[17] Evans RB, Truitt J, Watson GM. Interdiffusion of Helium and Argon in a Large-Pore Graphite. Journal of Chemical \& Engineering Data. 1961;6(4):522-5.

[18] Clark JD, Ghanthan CS, Robinson PJ. Investigation of pore structure by a non-steady-state gas diffusion technique. Journal of Materials Science. 1979;14(12):2937-40.

[19] Hawtin P, Gibson JA. The effect of diffusion and bulk gas flow on the thermal oxidation of porous carbons_-III. Ungraphitised carbons. Carbon. 1966;4(4):501-8.

[20] Hawtin P, Gibson JA. The effect of diffusion and bulk gas flow on the thermal oxidation of porous carbons - II. Diffusional effects in graphite at high temperatures. Carbon. 1966;4(4):489500.

[21] Hawtin P, Gibson JA, Huber RA. Air oxidation studies in a long graphite channel. Carbon. 1968;6(6):901-15.

[22] Hawtin P, Gibson JA, Murdoch R, Lewis JB. The effect of diffusion and bulk gas flow on the thermal oxidation of nuclear graphite-I. Temperatures below 500 ${ }^{\circ}$. Carbon. 1964;2(3):299309.

[23] Hawtin P, Huber RA. The effects of non uniform burn off on the kinetics of oxidation of large tubular specimens of graphite. Carbon. 1968;6(6):887-99.

[24] Hawtin P, Murdoch R. The role of in-pore mass transport resistance in the reaction of porous solids with gases The air oxidation of large tubes of graphite. Chemical Engineering Science. 1964;19(10):819-34.

[25] Hewitt GF, Sharratt EW. Gaseous Diffusion in Porous Media with Particular Reference to Graphite. Nature. 1963;198:952.

[26] Solcova O, Schneider P. Experimental Determination of Transport Parameters. In: Ho CK, Webb SW, eds. Gas Transport in Porous Media. Dordrecht, The Netherlands: Springer 2006.

[27] Bourke PJ, Gray MD, Denton WH. Oxidation of P.G.A. graphite by trace mixtures of CO2$\mathrm{CO}$ in helium. Journal of Nuclear Energy Parts A/B Reactor Science and Technology.

1966;20(6):441-50.

[28] Marsden BJ, Haverty M, Bodel W, Hall GN, Jones AN, Mummery PM, et al. Dimensional change, irradiation creep and thermal/mechanical property changes in nuclear graphite.

International Materials Reviews. 2016;61(3):155-82.

[29] Hinssen H-K, Kühn K, Moormann R, Schlögl B, Fechter M, Mitchell M. Oxidation experiments and theoretical examinations on graphite materials relevant for the PBMR. Nuclear Engineering and Design. 2008;238(11):3018-25.

[30] Pappano PJ, Burchell TD, Hunn JD, Trammell MP. A novel approach to fabricating fuel compacts for the next generation nuclear plant (NGNP). Journal of Nuclear Materials. 2008;381(1):25-38. 
[31] Tang C, Li Z, Zou Y, Fu X. Irradiation testing of matrix material for spherical HTR-10 fuel elements. Nuclear Engineering and Design. 2008;238(11):2886-92.

[32] Zhang W-t, Zhang B-1, Song J-1, Qi W, He X-j, Liu Z-j, et al. Microstructure and molten salt impregnation characteristics of a micro-fine grain graphite for use in molten salt reactors. New Carbon Materials. 2016;31(6):585-93.

[33] International A. Standard Specification for Isotropic and Near isotropic Nuclear Graphites. ASTM International 2014, p. 5.

[34] Petersen EE. Diffusion in a pore of varying cross section. AIChE Journal. 1958;4(3):343-5.

[35] Bentolila J. The preparation of graphite with a narrow spectrum of fine pores. Project

DRAGON: ; Atomic Energy Establishment, Winfrith, England (United Kingdom); 1965. Report

No.: DP-Report--161 United Kingdom OECD High Temperature Reactor Project Dragon Report. Now open access. DTIE English.

[36] Kee RJ, Coltrin ME, Glarborg P. Molecular Transport. Chemically Reacting Flow: John Wiley \& Sons, Inc. 2005, p. 487-539.

[37] Svehla RA. Estimated Viscosities and Thermal Conductivities of Gases at High

Temperatures: National Aeronautics and Space Administration; 1962.

[38] Marrero TR, Mason EA. Gaseous Diffusion Coefficients. Journal of Physical and Chemical Reference Data. 1972;1(1):3-118.

[39] Lang H, Loyalka S. Diffusion Slip Velocity: Theory and Experiment. Zeitschrift für Naturforschung A 1972, p. 1307.

[40] He Z, Gao L, Qi W, Zhang B, Wang X, Song J, et al. Molten FLiNaK salt infiltration into degassed nuclear graphite under inert gas pressure. Carbon. 2015;84(Supplement C):511-8.

[41] Huang W-H, Tsai S-C, Yang C-W, Kai J-J. The relationship between microstructure and oxidation effects of selected IG- and NBG-grade nuclear graphites. Journal of Nuclear Materials. 2014;454(1):149-58.

[42] Huang W-H, Tsai S-C, Chiu IC, Chen C-H, Kai J-J. The oxidation effects of nuclear graphite during air-ingress accidents in HTGR. Nuclear Engineering and Design.

2014;271(Supplement C):270-4.

[43] Chen D, Li Z, Miao W, Zhang Z. Effects of Porosity and Temperature on Oxidation Behavior in Air of Selected Nuclear Graphites. Materials Transactions. 2012;53(6):1159-63. [44] Li Z, Chen D, Fu X, Miao W, Zhang Z. The Influence of Pores on Irradiation Property of Selected Nuclear Graphites. Advances in Materials Science and Engineering. 2012;2012:6. [45] J. Rouquerol DA, C. W. Fairbridge, D. H. Everett, J. M. Haynes, N. Pernicone, J. D. F. Ramsay, K. S. W. Sing and K. K. Unger. Recommendation for the Characterization of Porous Solids. Pure Appl Chem. 1994;66(8):20. 


\section{Supplemental Material}

\section{Normal Diffusion Coefficient for Binary Gas Mixtures}

Diffusion coefficients for binary gas mixtures composed of species $j$ and $k$ were calculated according to the following equation:

$D_{j k}=\frac{3}{16} \frac{\sqrt{2 \pi k_{B}{ }^{3} T^{3} / m_{j k}}}{P \pi \sigma_{j k}{ }^{2} \Omega_{j k}{ }^{(1,1) \star}}$

$D_{j k}$ has dimensions of length ${ }^{2} /$ time . Here, $\pi$, has its usual meaning and $T$ and $P$ represent temperature and pressure respectively. $k_{B}$ is the Boltzmann constant, $m_{j k}$ is the reduced mass of the gas pair, and $\Omega_{j k}{ }^{(1,1) \star}$ represents a reduced collision integral. The reduced collision integral accounts for the departure from a classic "hard-sphere" assumption.

For $\mathrm{Ar}$ and $\mathrm{N}_{2}$ the following relation is a good approximation for $\Omega_{j k}{ }^{(1,1) \star}[1]$ :

$\Omega_{j k}^{(1,1) \star} \approx a_{1} T_{j k}^{*-a_{2}}+\left(T_{j k}^{*}+a_{3}\right)^{-a_{4}}$

where

$T_{j k}^{*}=\frac{T k_{B}}{\varepsilon_{j k}}$

and

Table S.1 Coefficients for fit of $\Omega_{j k}^{(1,1) \star}[1]$

\begin{tabular}{c|cccc}
\multicolumn{1}{c}{} & $j=1$ & $j=2$ & $j=3$ & $j=4$ \\
\hline$a_{j}$ & 1.0548 & 0.15504 & 0.55909 & 2.1705
\end{tabular}

The reduced collision integral used here relies upon the Lennard-Jones (power law attraction and repulsion) potential parameters $\sigma_{j k}$ and $\varepsilon_{j k} . \sigma_{j k}$ is the intermolecular separation distance where the interaction potential between a molecule of species $j$ and $k$ vanishes and $\varepsilon_{j k}$ is an energy "well" depth. These parameters have the following approximate functional form relative to the parameters for individual species:

$\sigma_{j k} \approx \frac{1}{2}\left(\sigma_{j j}+\sigma_{k k}\right)$

$\varepsilon_{j k} \approx\left(\frac{\varepsilon_{j j}}{k_{B}}+\frac{\varepsilon_{k k}}{k_{B}}\right)^{1 / 2}$

The parameters for individual species were taken from a NASA technical report by Roger A. Svehla [2]. 
Although experimental values for the Ar- $\mathrm{N}_{2}$ binary system are available [3], the authors preferred the above method as it more easily lends itself to high temperature approximation of effective gaseous diffusion coefficients at temperatures relevant to graphite oxidation in nuclear reactors. Values obtained using Eq. 1 agreed reasonably well with room temperature experimental measurements [3].

1.1 Composition Dependence of Normal Diffusion Coefficient Using Eq. 1, as a first approximation of the binary diffusion coefficient, a second approximation can be obtained via the following relationship:

$D_{j k_{2}}=D_{j k_{1}}\left(1+\Delta_{j k}\right)$

where

$\Delta_{j k}=\frac{6 C_{j k}{ }^{\star}-5}{10}\left(\frac{y_{j}{ }^{2} \Phi_{j}+y_{k}{ }^{2} \Phi_{k}+y_{j} y_{k} \Phi_{j k}}{y_{j}{ }^{2} \Theta_{j}+y_{k}{ }^{2} \Theta_{k}+y_{j} y_{k} \Theta_{j k}}\right)$

In Eq. 7, $y$ represents the mole fraction of species $j$ or $k$. Additionally, $C_{j k}$ is the ratio of the $\Omega_{j k}{ }^{(1,2) \star}$ and $\Omega_{j k}{ }^{(1,1) \star}$ reduced collision integrals and the $\Phi$ 's and $\Theta$ 's are complicated algebraic expressions described in detail elsewhere [3]. The second approximation takes into account the usually small changes in the binary diffusion coefficient with gas composition.

\section{3-D Tortuosity Measurements from X-ray Computed Tomography}

Details regarding the variety of X-ray tomographic systems and scanning parameters used for the individual X-ray tomography experiments will be published at a later date in a detailed peerreviewed manuscript. Here, however, some detail is merited on the methodology used for the calculation of geodesic tortuosity for IG-110 and NBG-18 nuclear grade graphites shown in Fig. $5 b$ of the main text.

The calculations discussed below were performed on high performance computing resources at Idaho National Laboratory using Matlab 2017 b.

The starting input for the calculation of tortuosity was a stack of unsigned, 16 bit, gray-scale images representing a cylindrical graphite sample and its inherent porosity. The general steps of the procedure are listed sequentially below:

1. Ensure graphite cylinder's axis of symmetry is perpendicular to the XY image plane of the data volume.

a. If not aligned, rotate volume to achieve alignment

2. Filter the data volume to minimize the noise in volume without blurring feature edges.

a. Use a small filter kernel.

3. Define a 3-D mask to separate the air outside the sample volume from the cylindrical sample space.

4. Selectively segment porosity within the graphite from the solid graphite material.

a. If the data volume is of high quality and has a high signal to noise ratio a global threshold should provide an accurate segmentation. 
i. A local adaptive method may be needed for low quality data volumes.

b. The 3-D mask is used to distinguish porosity from "air" outside the sample volume.

5. Isolate the open pore network from isolated (closed) pores.

a. A connective components algorithm can be used.

The five steps listed above may be used to generate a binary volume representing the majority of the open pore network within IG-110 and NBG-18 grade nuclear graphites. The following steps were used to transform the data volume such that tortuosity measurements of the open pore network could be made.

1. Choose seed points for a geodesic distance transform

a. For this work, the voxels (3-D equivalent of pixel) representing pore space in the top and bottom slices along the z-axis (parallel to the cylindrical symmetry axis) were used as seed points for the transform.

b. The top and bottom sets of voxels need to be considered separately.

2. Perform a geodesic distance transform using the top slice as seed points for the transform.

a. This work used an Accurate Multi-Stencil Fast Marching Algorithm.

b. The "Speed Map" used ones for voxels belonging to the pore space and a value of $10^{-5}$ for all other voxels.

3. Repeat the process separately with the bottom slice as seed points for the transform.

4. Sum the results of both transforms together and account for numerical round-off error.

The result of the summation above is essentially a geodesic "distance map." The distance value at each voxel represents the shortest possible distance from the top to bottom slice passing through the voxel of interest. If the entire distance map is divided by the Euclidean distance between the two slices (equivalent to two parallel planes) the resulting values are equivalent to the geodesic tortuosity of each voxel.

The histograms shown in Figure $5 \mathrm{~b}$ for IG-110 and NBG-18 were made from a random sample of $10^{7}$ voxels within the open pore network of each grade. The average values shown are the mean of the entire sample populations and are equivalent to a mean volumetrically averaged tortuosity.

\section{References}

[1] R.J. Kee, M.E. Coltrin, P. Glarborg, Molecular Transport, Chemically Reacting Flow, John Wiley \& Sons, Inc.2005, pp. 487-539.

[2] R.A. Svehla, Estimated Viscosities and Thermal Conductivities of Gases at High Temperatures, National Aeronautics and Space Administration Technical Reports, National Aeronautics and Space Administration, 1962, pp. 1-119.

[3] T.R. Marrero, E.A. Mason, Gaseous Diffusion Coefficients, Journal of Physical and Chemical Reference Data 1(1) (1972) 3-118. 